\title{
GERMINACIÓN DE UNA ESPECIE ORNITOCORA Y UNA ANEMÓCORA DE LA ISLA NAVARINO, RESERVA DE BIOS- FERA CABO DE HORNOS*
}

\section{GERMINATION OF ORNITOCORE AND ANEMOCORE SPECIES FROM NAVARINO ISLAND, CAPE HORN BIOSPHERE RESERVE, CHILE}

\author{
Jofre, J.', Vera, M.' y Massardo, F. ${ }^{2}$ \\ 'Escuela de Recursos Naturales Renovables y Acuáticos. \\ ${ }^{2}$ Parque Etnobotánico Omora, Sede Puerto Williams, Universidad de Magallanes; Correo \\ Puerto Williams, XII Región. E-mail: francisca.massardo@umag.cl
}

\section{INTRODUCCIÓN Y OBJETIVOS}

La región del Cabo de Hornos ha sido recientemente declarada Reserva de Biosfera (junio 2005) debido a sus características únicas de pristinidad, singularidad biológica y belleza paisajística. Como estrategia de conservación biológica y uso sustentable de la biodiversidad, la construcción de un banco de germoplasma permite el estudio y propagación ex-situ de especies de plantas nativas que crecen en el extremo austral de América. Un primer paso para alcanzar este fin corresponde al estudio del comportamiento de germinación y técnicas para la propagación ex situ a través de semillas de especies de interés de la región subantártica chilena.

Entre las plantas vasculares con valor ornamental en los bosques de canales de la ecoregión subantártica de Magallanes este estudio investiga la germinación en dos especies: una arbórea, el canelo (Drimys winteri), y otra arbustiva, el romerillo enano, Baccharis magellanica. El canelo es una Winteraceae leñosa de brillante follaje siempreverde, aromáticas flores blancas polinizadas por insectos y frutos carnosos consumidos y dispersados por aves. B. magellanica es una Asteraceae perenne, rastrera, clasificada como cubrepiso por su follaje de hojas pequeñas y de delicado color verde. Desde el punto de vista ecológico, los hábitos de dispersión de semillas de ambas especies son diferentes: por aves frugívoras en el caso de $D$. winteri (ornitocoría) y por viento (anemocoría) en B. magellanica.
Los objetivos de este trabajo son el estudio de la germinación de semillas de $D$. winteri $y$ de B. magellanica, y la comparación de sus conductas de germinación evaluando el efecto que podría tener sobre ésta los síndromes de dispersión de semillas bióticos y abióticos. Con este fin, se investiga la germinación directa de las semillas de ambas especies y la germinación de semillas que han pasado por el tracto digestivo de aves en el caso de $D$. winteri.

\section{MATERIAL Y MÉTODOS}

La colecta de semillas se realizó para ambas especies en la costa norte de la isla Navarino $\left(55^{\circ} \mathrm{S}\right)$. En el caso de $D$. winteri las semillas se obtuvieron en el Parque Etnobotánico Omora, campus experimental de la Universidad de Magallanes ubicado $3 \mathrm{~km}$ al oeste de Puerto Williams, en mayo del 2005. Se colectaron frutos maduros de 20 individuos, y se obtuvieron semillas que pasaron por el tracto digestivo de aves a partir de fecas frescas de aves depositadas sobre hojas de los árboles y que contenían semillas de canelo. En el caso de B. magellanica los aquenios se colectaron en márgenes de bosque en sectores ubicados entre 15 y $30 \mathrm{~km}$ al oeste de Puerto Williams, en febrero del 2005. Las semillas de las dos especies se limpiaron y se mantuvieron refrigeradas a $8^{\circ} \mathrm{C}$. Las semillas se caracterizaron (semillas $\mathrm{g}^{-1}$, viabilidad, \% de humedad, curva de imbibición) y se evaluó la germinación natural de las dos especies en un sistema de placas Petri con papel absorbente 
a $22^{\circ} \mathrm{C}$. Como tratamientos de germinación se aplica estratificación a $4 \pm 1^{\circ} \mathrm{C}$ y aplicación de hormonas.

\section{RESULTADOS Y CONCLUSIÓN}

Los resultados obtenidos hasta la fecha muestran que las semillas $(\mathrm{N}=225)$ de $B$. magellanica presentan más de un $92 \%$ de germinación natural, esto es sin tratamiento pregerminativo de escarificación o estratificación. Por lo tanto, las semillas de esta especie de cubrepiso nativo no ofrecen dificultades para su propagación ex situ, facilitando su potencial utilización ornamental. Para este último propósito será necesario evaluar las fases de establecimiento y crecimiento de plántulas.

En contraste las semillas de la especie ornitó- cora, D. winteri, no presentaron germinación natural. Ninguna de las semillas obtenidas tanto del fruto $(\mathrm{N}=300)$ como de las fecas $(\mathrm{N}=60)$ tuvo emergencia de radícula. La inspección con microscopía estereoscópica de estas últimas semillas demostraron que el paso por el intestino de las aves no provoca ruptura o daño aparente de las semillas de canelo, notándose un resquebrajamiento de la testa. En este momento, una muestra de 600 semillas se encuentra en tratamiento de estratificación a $4 \pm 1^{\circ} \mathrm{C}$ por períodos $1440,2160,2880$ y 3600 horas de exposición. Este experimento permitirá evaluar la importancia del tratamiento con frío para lograr la germinación de este hermoso árbol nativo que logra crecer en los bosques más australes del planeta.*

Agro Sur 34 (1-2):51 -52 2006

\title{
CARACTERIZACION FISICOQUIMICA DE TURBAS DE SPHAGNUM DE ORIGEN ARGENTINO
}

\section{PHYSICO - CHEMICAL CHARACTERIZATION OF SPHAGNUM PEATS OF ARGENTINE ORIGIN}

\author{
Morisigue, D.; Karlanián, M.; Wicky, M.; Mata, D. \\ INTA, Instituto de Floricultura, de los Reseros y Las Cabanas, (1712) - Castelar, Argentina. \\ E-mail: dmorisigue@enia.inta.gov.ar
}

\section{INTRODUCCIÓN Y OBJETIVOS}

La turba de sphagnum es uno de los materiales mas usados en la preparación de sustratos de cultivos intensivos (Fonteno, 1996). En Argentina a comienzos de la década de los noventa, con la introducción de tecnología, se introdujo la turba proveniente del Hemisferio Norte para la preparación de diferentes medios de cultivos. Luego del cambio en el escenario económico a partir del año 2001, ha mermado considerablemente la disponibilidad del material importado, pero la demanda y el potencial mercado hizo que surgieran varios proveedores de turbas de origen argentino, especialmente proveniente de la Provincia de Tierra del Fuego. Con el objeto de estudiar su aptitud para ser usada como sustrato en el cultivo de plantas ornamentales, se han caracterizado física y químicamente 4 turbas de origen nacional.

\section{MATERIALES Y MÉTODOS}

Las muestras de turba fueron obtenidas de bolsas comerciales disponibles en el mercado. La caracterización física y química se hizo siguiendo el protocolo desarrollado en el laboratorio de sustratos y agua del Instituto de Floricultura. De los parámetros físicos se ha medido humedad, densidad, granulometría y porosidad. Los parámetros químicos que se han evaluado son $\mathrm{pH}$, conductividad eléctrica (CE) y concentración de nitrato, $\mathrm{Ca}, \mathrm{K}, \mathrm{Mg}$ y $\mathrm{Na}$.

\section{RESULTADOS}

El análisis granulométrico en peso (expresado en porcentaje), ha mostrado para las turbas A 